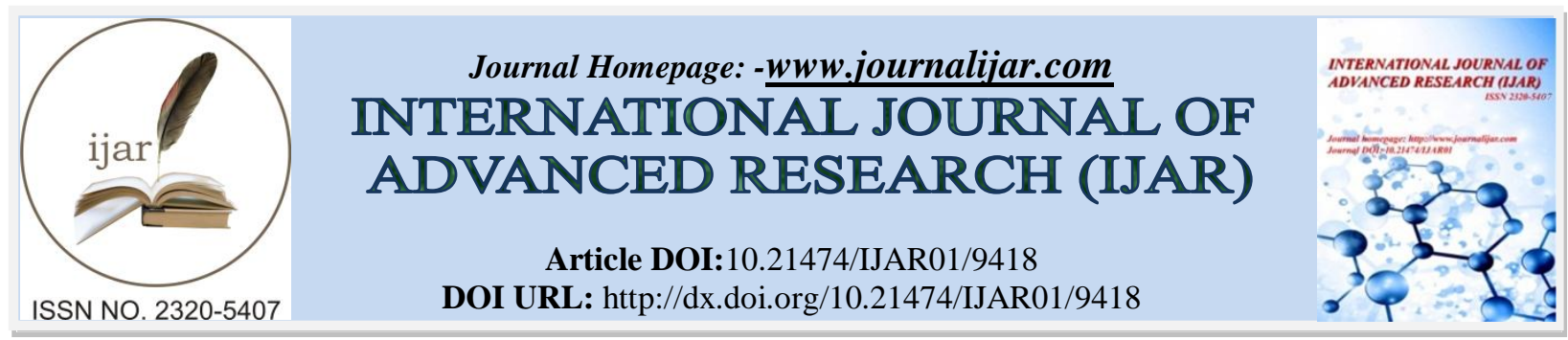

RESEARCH ARTICLE

\title{
ASSESSMENT OF ANTIMICROBIAL ACTIVITY OF MORINGA OLEIFERA AND AZADIRACHTA INDICA LEAVES AGAINST ENTEROCOCCUS FAECALIS, CANDIDA ALBICANS - AN INVITRO STUDY.
}

\section{Bhavya Shetty, Suchitra Vijay, Shreema Shetty and Shruti Bhandary. \\ Department Of Conservative Dentistry and Endodontics, A J Institute of Dental sciences ,Mangalore,Karnataka,} India.

\section{Manuscript Info}

\section{Manuscript History}

Received: 22 May 2019

Final Accepted: 24 June 2019

Published: July 2019

Keywords: Moringa oleifera, Azadirachta indica, Enterococcus faecalis, Candida albicans.

\begin{abstract}
Objective: To evaluate the antibacterial activity of triple antibiotic paste, Moringa oleifera, Azadirachta indica against Enterococcus faecalis and Candida albicans. Methods: .The extracts of Azadirachta indica and Moringa oleifera were prepared in vitro and the antibacterial effect of the extracts against Enterococcus faecalis and Candida albicans was evaluated using the agar diffusion technique. Results:The study showed that A.indica has a highest inhibitory growth (17.0mm) followed by A.indica and M.oleifera combination (16mm) against E. faecalis and C.albicans, and M.oleifera has the least inhibitory growth $(14.00 \mathrm{~mm})$.Conclusion: According to this study, A. indica and M.oleifera demonstrated an antibacterial effect against E. faecalis and C.albicans.
\end{abstract}

Copy Right, IJAR, 2019, All rights reserved.

\section{Introduction: -}

Endodontic therapy aims at the elimination of bacteria, their byproducts and pulpal remnants from root canal space by mechanical instrumentation as well as by chemical irrigation of pulpal space. Proper instrumentation and irrigation of the root canal space plays an important role in success of the treatment $[1,2,3]$.

The endodontic microbial flora is comprised of various microbes present in the oral cavity which consist of anaerobic bacterial species, some fungal and viral species. Of these Enterococcus Faecalis and Candida Albicans are among the most important microbes isolated from the infected root canals $[4,5]$.

Enterococcus Faecalis is a facultatively anaerobic gram-positive cocci. They occur singly in pairs or in short chains and are frequently elongated in the direction of chain [1].It has been only occasionally found in cases of primary endodontic infections but more frequently detected in cases in which endodontic therapy has failed. According to studies $45.8 \%$ failures are caused by Enterococcus faecalis, followed by Peptostreptococcus, Candida albicans and Actinomyces [3] E. faecalis is the species that can best adapt to and tolerate the ecologically demanding condition in the root canals. Eradication of this species from root canal space is difficult to achieve $[6,7]$

Candida albicans is a normal part of the human commensal flora, however it is also the most common fungal species that can cause human disease. Candida albicans has a major role in endodontic treatment failure and is the most important fungus isolated from the root canal system. the change of Candida albicans from an innate microorganism to a pathogenic one depends on minor changes in various pathogenic characteristics such as adhesion 
factor, hyphae formation, proteinase secretion and phenotypic switching phenomenon. It has the ability to invade dentinal tubules.[8]

Natural products play an important role in human life and various plants have been used as a source of medicine since many years. Hence there is an increased interest in identifying and using various plant sources as medicine and many studies are being carried out for the same[9].Thus this study aims at evaluating the antimicrobial efficacy of moringa oleifera and azadirachta Indica against two of the predominant persistent microbes that is E.faecalis and C.albicans and compare it with triple antibiotic paste.

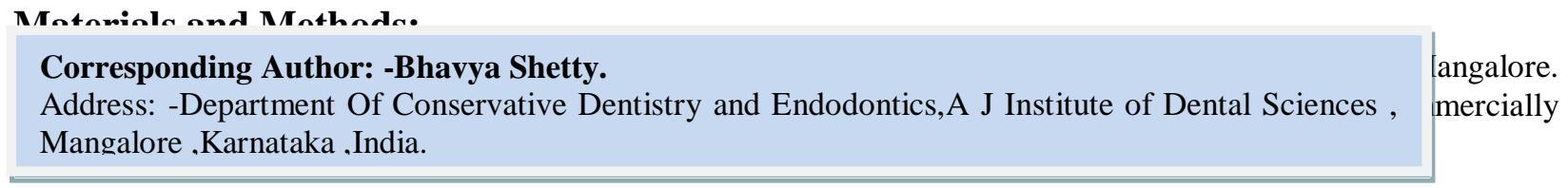

\section{Preparation of Extracts}

$50 \mathrm{~g}$ of moringa oleifera leaves powder was soaked in about $250 \mathrm{ml}$ of ethanol $(95 \%)$ for 48 hours at room temperature. The soaked mixture was then magnetically stirred (REMI 1MLH) at 800rpm for 4 hours to obtain a homogenous mixture and then stored at $4^{\circ} \mathrm{C}$ for 24 hours to allow the extraction of active constituents .Extracts were then filtered off using Whatman No.1 filter paper and concentrated by using rotary flash evaporator (Superfit Rotary Vacuuma Digital Bath) at controlled temperature (figure 1)

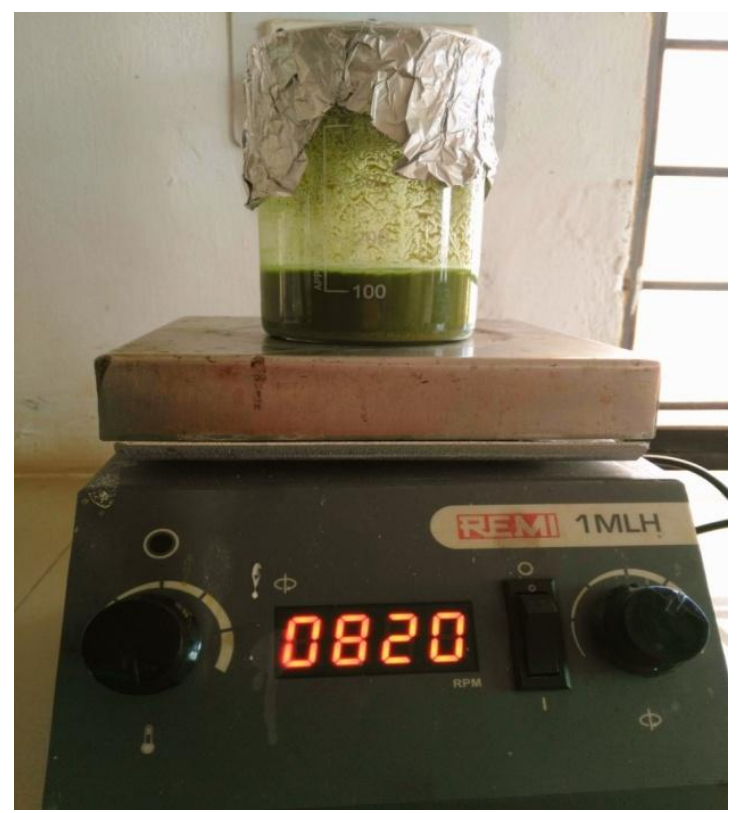

Figure 1:-Extract of moringa leaves preparatory procedure)

Triple antibiotic paste was prepared for each group with identical amount of the three antibiotic powders (mg) and then mixed with $1 \mathrm{ml}$ normal saline.

\section{Preparation of Media \\ Mueller Hinton Agar}

Weighed 38.0 grams of media and transferred into a conical flask containing $1000 \mathrm{ml}$ distilled water. Boiled to dissolve the medium completely. Sterilized by autoclaving at $15 \mathrm{lbs}$ pressure $\left(121^{\circ} \mathrm{C}\right)$ for 15 minutes. Cooled to 45 $50^{\circ} \mathrm{C}$ before adding into sterile petriplates.

\section{Sabouraud Dextrose Agar}

Weighed 65.0 grams of media and transferred into a conical flask containing $1000 \mathrm{ml}$ distilled water. Boiled to dissolve the medium completely. Sterilized by autoclaving at $15 \mathrm{lbs}$ pressure $\left(121^{\circ} \mathrm{C}\right)$ for 15 minutes. Cooled to 45 $50^{\circ} \mathrm{C}$ before adding into sterile petriplates. 


\section{Preparation of Extract Concentrate}

$10 \mathrm{~g}$ of the concentrated extract is taken and dissolved in $20 \mathrm{ml}$ of sterile water for injection. (500mg/ml). The above stock solution is added to the prepared wells on the solidified agar plate $\left(40^{\circ} \mathrm{C}\right)$ to evaporate the solvent used for extraction.

\section{Antimicrobial Activity \\ Agar Diffusion Method}

To the prepared media, the required bacterial suspension is inoculated. Media is transferred to the sterile Petri plates and allowed to solidify. A sterile cork borer of $6 \mathrm{~mm}$ diameter was used to punch wells on the agar on each of the petri dishes. The holes were filled with $0.5 \mathrm{ml}$ of prepared extracts. Control experiments were also carried out where the holes were filled with $0.5 \mathrm{ml}$ Triple antibiotic paste.

Then, the plates were incubated at $35-37^{\circ} \mathrm{C}$ for 24 hours (figure 2 and figure 3 ). After the incubation period, the antimicrobial activity was evaluated by determining the zone of inhibition $(\mathrm{mm})$ around each well of extract solution.

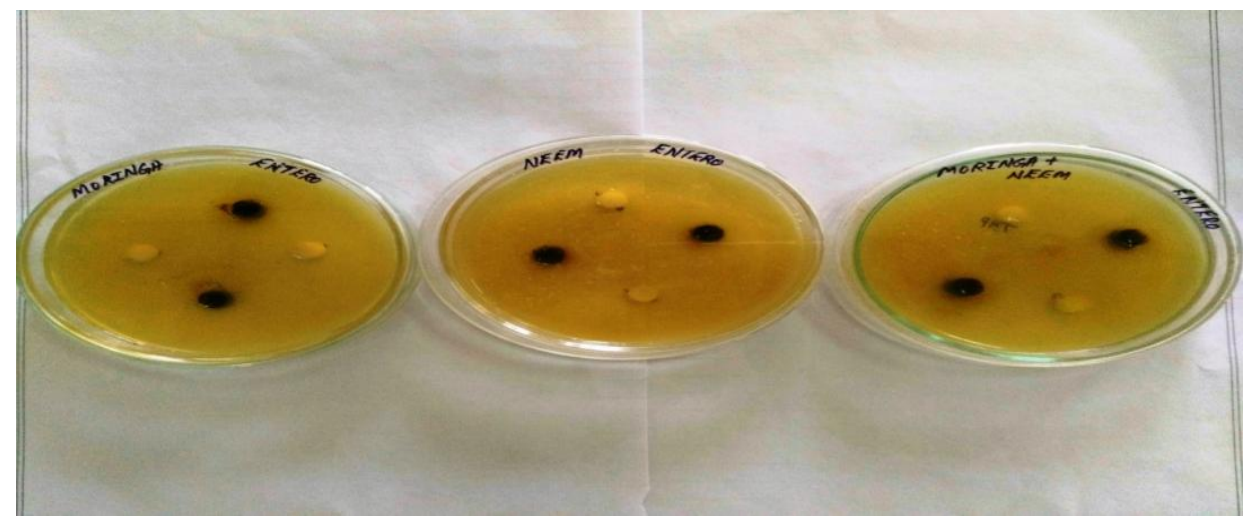

Figure 2:-Antimicrobial activity (Prepared plates)

M.oleifera+E.faecalis,A.indica+E.faecalis,M.oleifera+A.indica+E.faecalis

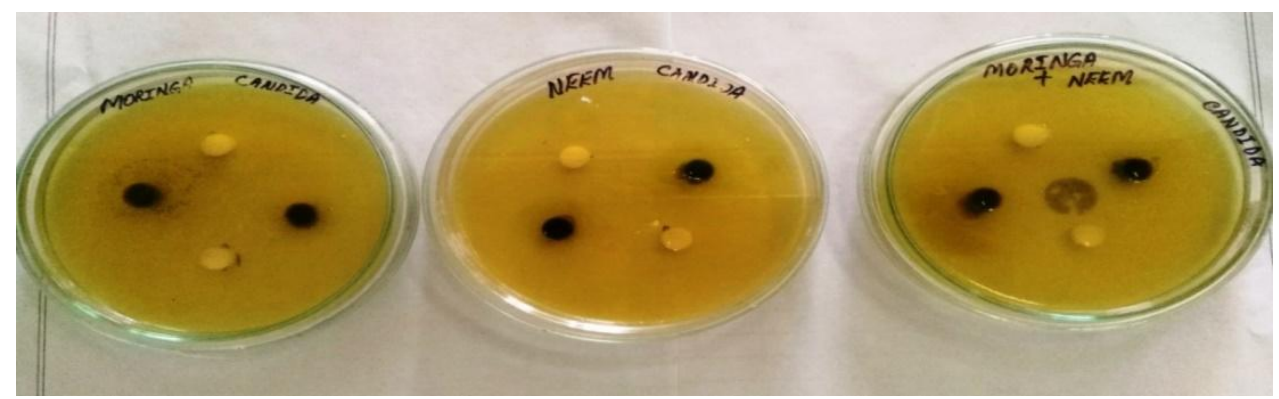

Figure 3:-Antifungal activity (Prepared plates)

M.oleifera+C.albicans, Aindica+C.albicans, M.oleifera+A.indica + C.albicans 


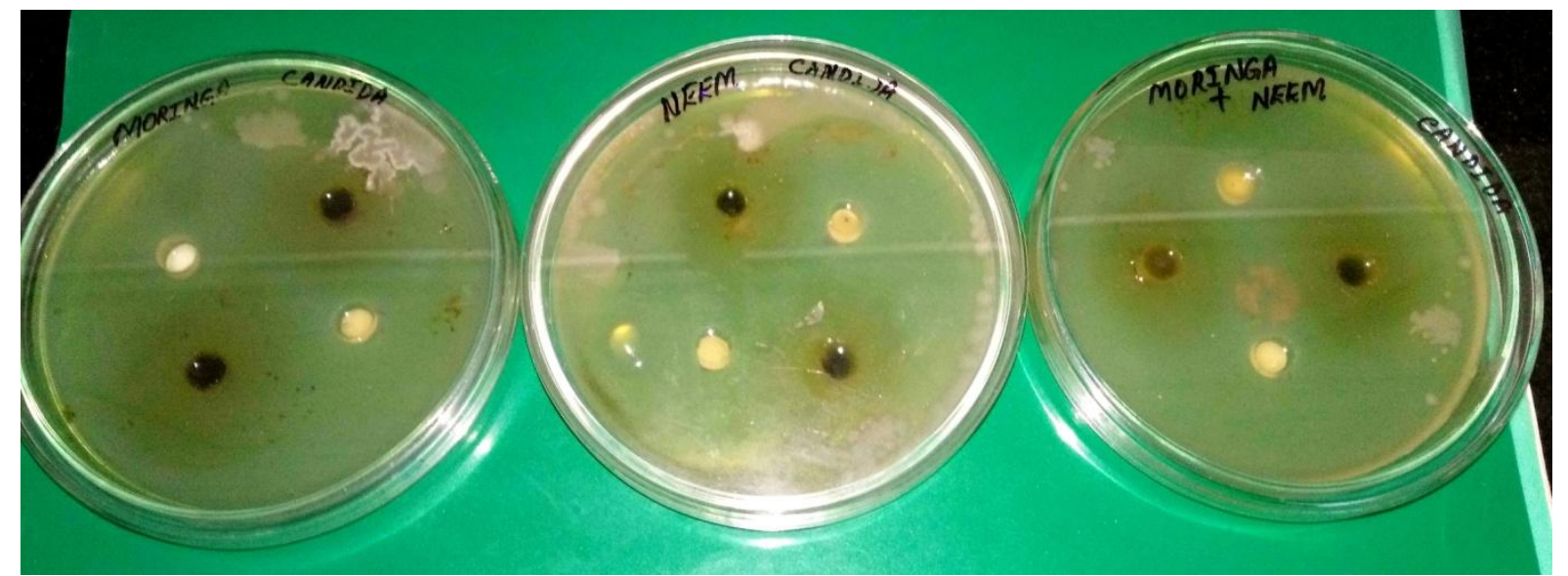

Figure 4:- Zone of inhibition (in mm) M.oleifera+C.albicans,A.indica+C.albicans,M.oleifera+A.indica+C.albicans

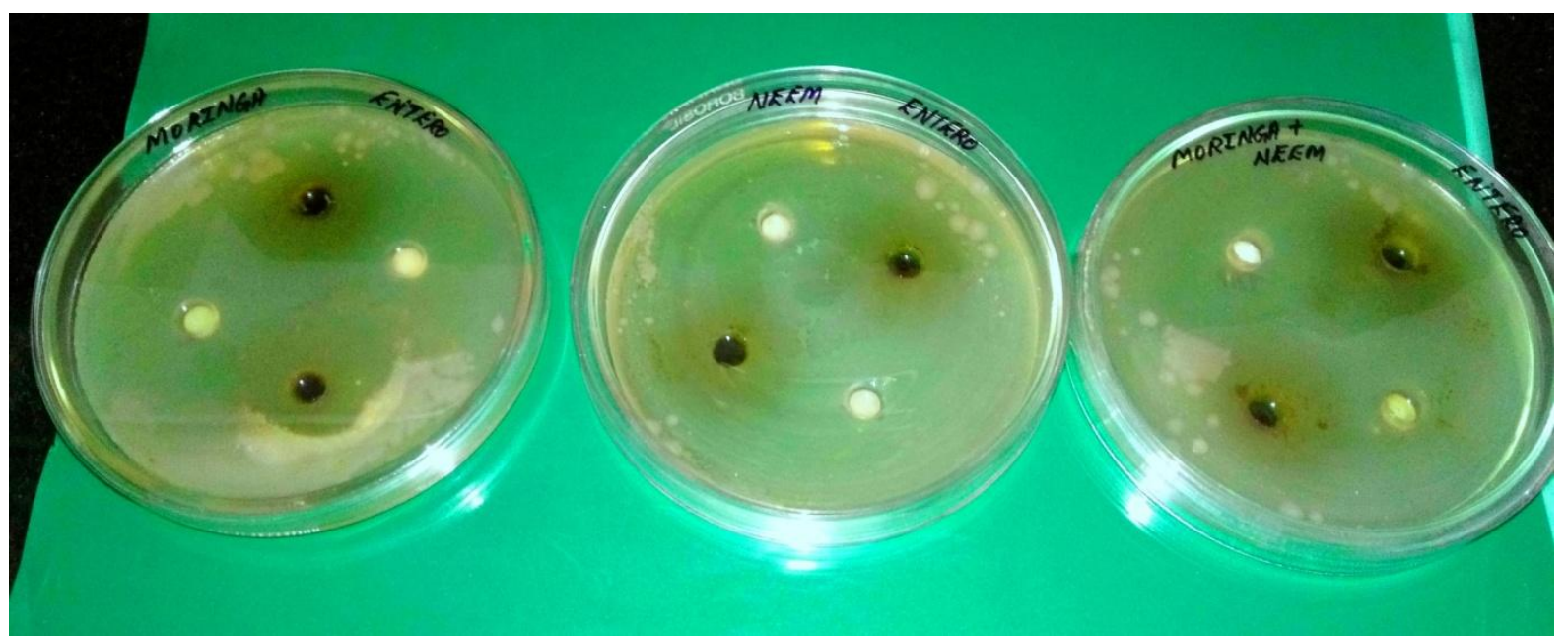

Figure 5:- Zone of inhibition (in mm)M.oleifera+E.faecalis,A.indica+E.faecalis,M.oleifera+A.indica+E.faecalis

\section{Statistical Analysis}

The collected data was analyzed using the following statistical test

1. Kruskal Wallis test (Table 5, Table 6)

2. Mann-Whitney test (Table 7)

\section{Results:-}

The current study showed that Azadirachta indica has a highest inhibitory growth followed by Azadirachta indica and Moringa oleifera combination against E. faecalis, C.albicans and Moringa oleifera has the least inhibitory growth. The diameter of inhibition zones is tabulated in tables 1-4.

\begin{tabular}{|l|l|l|l|l|}
\hline MORINGA OLEIFERA & PLATE 1 & PLATE 2 & PLATE 3 & PLATE 4 \\
\hline \multirow{2}{*}{ E. FAECALIS } & 15 & 15 & 16 & 15 \\
\cline { 2 - 5 } & 16 & 16 & 17 & 16 \\
\hline \multirow{2}{*}{ CANDIDA } & 12 & 12 & 13 & 12 \\
\cline { 2 - 5 } & 14 & 13 & 12 & 13 \\
\hline
\end{tabular}

Table1:-Diameter of inhibition zone in millimeter observed around Moringa oleifera 


\begin{tabular}{|l|l|l|l|l|}
\hline \multicolumn{2}{|l|}{ AZADIRACHTA INDICA } & PLATE 2 & PLATE 3 & PLATE 4 \\
\hline \multirow{2}{*}{ E.FAECALIS } & PLATE 1 & 19 & 17 & 18 \\
\cline { 2 - 5 } & 18 & 18 & 17 & 18 \\
\hline \multirow{2}{*}{ CANDIDA } & 16 & 16 & 15 & 17 \\
\cline { 2 - 5 } & 15 & 15 & 16 & 16 \\
\hline
\end{tabular}

Table 2:-Diameter of inhibition zone in millimeter observed around Azadirachta indica

\begin{tabular}{|l|l|l|l|l|}
\hline MORINGA OLIEFERA+AZADIRACHTA INDICA \\
\hline \multirow{2}{*}{ E.FAECALIS } & PLATE 1 & PLATE 2 & PLATE 3 & PLATE 4 \\
& 17 & 16 & 17 & 18 \\
\cline { 2 - 5 } & 17 & 16 & 17 & 19 \\
\hline \multirow{2}{*}{ CANDIDA } & 14 & 13 & 14 & 14 \\
\cline { 2 - 5 } & 13 & 14 & 13 & 15 \\
\hline
\end{tabular}

Table 3:-Diameter of inhibition zone in millimeter observed around M.oleifera + A.indica

\begin{tabular}{|l|l|l|l|l|}
\hline \multicolumn{5}{|l|}{ TRIPLE ANTIBIOTIC PASTE } \\
\hline \multirow{2}{*}{ E. FAECALIS } & PLATE 1 & PLATE 2 & PLATE 3 & PLATE 4 \\
& 20 & 19 & 19 & 19 \\
\cline { 2 - 5 } & 19 & 19 & 18 & 20 \\
\hline \multirow{2}{*}{ CANDIDA } & 19 & 20 & 21 & 20 \\
\cline { 2 - 5 } & 20 & 21 & 21 & 20 \\
\hline
\end{tabular}

Table 4:-Diameter of inhibition zone in millimeter observed around Triple Antibiotic Paste

\begin{tabular}{|l|l|l|l|l|l|l|l|}
\hline & N & Minimum & Maximum & Mean & SD & $\begin{array}{l}\text { Kruskal } \\
\text { Wallis }\end{array}$ & P Value \\
\cline { 1 - 6 } Moringa & 8 & 12 & 14 & 12.63 & .744 & 27.81 & \multirow{2}{*}{$0.00^{*}$} \\
\cline { 1 - 5 } Neem & 8 & 15 & 17 & 15.75 & .707 & & \\
\cline { 1 - 5 } Moringa+Neem & 8 & 13 & 15 & 13.75 & .707 & \\
\cline { 1 - 5 } & 8 & 19 & 21 & 20.25 & .707 & & \\
\hline
\end{tabular}

Table 5:-Comparison of candida albicans among groups using kruskal-wallis test

\begin{tabular}{|c|c|c|c|c|c|c|c|}
\hline & $\mathbf{N}$ & Minimum & Maximum & Mean & SD & $\begin{array}{l}\text { Kruskal } \\
\text { Wallis }\end{array}$ & P Value \\
\hline Moringa & 8 & 15 & 17 & 15.75 & .707 & \multirow[t]{4}{*}{23.03} & \multirow[t]{4}{*}{$0.00^{*}$} \\
\hline Neem & 8 & 17 & 19 & 17.75 & .707 & & \\
\hline Moringa+Neem & 8 & 16 & 19 & 17.13 & .991 & & \\
\hline Tap & 8 & 18 & 20 & 19.12 & .641 & & \\
\hline
\end{tabular}

Table 6:-Comparison of Enterococcus faecalis among groups using kruskal-wallis test

\begin{tabular}{|c|c|c|c|c|c|}
\hline \multirow[b]{2}{*}{ Group } & \multirow[b]{2}{*}{ Groups } & \multicolumn{2}{|l|}{ E.FAECALIS } & \multicolumn{2}{|l|}{ CANDIDA } \\
\hline & & Mean Difference & P value & Mean difference & P value \\
\hline \multirow[t]{3}{*}{ Moringa } & Neem & -2.00 & $0.001 *$ & -3.12 & $0.001 *$ \\
\hline & $\begin{array}{l}\text { Moringa+ } \\
\text { Neem }\end{array}$ & $-1.375^{*}$ & $0.008^{*}$ & -1.12 & 0.013 \\
\hline & Tap & $-3.375^{*}$ & $0.001 *$ & -7.6 & $0.001 *$ \\
\hline \multirow[t]{2}{*}{ Neem } & $\begin{array}{l}\text { Moringa+ } \\
\text { Neem }\end{array}$ & 0.625 & 0.13 & 2.00 & $0.001 *$ \\
\hline & Tap & $-1.375^{*}$ & $0.004 *$ & -4.5 & $0.001 *$ \\
\hline Moringa+Neem & Tap & $-2.000 *$ & $0.002 *$ & -6.5 & $0.001 *$ \\
\hline
\end{tabular}

Table 7:-Comparison among groups using Post- hoc (mann-whitney test) 


\section{Discussion:-}

In this study, we evaluated the medicinal plants such as M.oleifera and A.indica for their antimicrobial activity against pathogens such as E.faecalis and C.albicans

Enterococcus faecalis is a microorganism commonly detected in asymptomatic, persistent endodontic infections. Its prevalence in such infections ranges from $24 \%$ to $77 \%$. This finding can be explained by various survival and virulence factors possessed by E. faecalis, including its ability to compete with other microorganisms, invade dentinal tubules, and resist nutritional deprivation.It suppresses the action of lymphocytes thereby contributing to endodontic failure.Root canals doesn't provide a nutrient rich medium for the survival of microbes even then E.faecalis survive on the components from the dentinal fluid.Hence even in a well debrided canals also there are chances of remaining cells of E.feacalis to grow . $(10,11)$

Candida albicans is adaptive oral yeast that can occasionally be isolated from the root canal in cases of persistent apical periodontitis both in pure culture and together with bacteria. $\mathrm{C}$ albicans adapt to an extremes range of $\mathrm{pH}$, low oxygen and nutritional environment. Candida is polymorphic fungus that exists in blastophores, germ tubes, true hyphae, pseudohyphae and chlamydospores depending on environmental conditions which helps in survival. Provides ability to penetrate dentinal tubules via hyphal adherance and able to bind to collagen types I and IV. . In a study carried out by Sen et al. Candida albicans was reported to be the most prevalent pathogenic fungus isolated from the oral cavity and was called a dentinophilic microorganism because of its ability to invade dentinal tubules. Within tubules, the microorganism may be protected from the lethal action of endodontic medicaments by the inactivating effects by dentin[12].

Hence it is necessary to study about new antimicrobial agents specific for this organisms for a better outcome of endodontic therapy. Azadirachta indica and Moringa oleifiera are having medicinal value and are used as a traditional household remedy for various ailments. Azarchdicta indica has analgesic, antifungal,antibacterial,antiviral and antiulcer properties while Moringa oleifiera has been reported to have antiviral,antioxidant,antisclerotic, antibacterial and anti-inflammatory properties.M.oleifiera also known as miracle tree because all the parts of the tree (leaves,pods,seeds,roots,flowers)can be utilized for nutritional ,ayurvedic and pharmacological benefits. The selection of these plants to evaluate their antimicrobial activity were based on these properties[13,14].

The presence of high concentrations of azadirachtins, quercetin and $\beta$ sitosterol in A. Indica leaves might be responsible for strong antibacterial and antifungal activity according to studies.azadirachtin is a cellular membrane synthesis inhibitor. The presence of nimbidin, Azadirachtin, and nimbinin help to remove many oral aerobic and anaerobic pathogens existing in the oral cavity[15,16].

The antibacterial effect of M. oleifera is due to the chemicalcompound4-(4'-O-acetyl- $\alpha$-L-rhamnopyranosyloxy) benzylisothiocyanate, whose mechanism of action involves inhibition of essential cellular membrane enzymes [17].

According to Alireza et al, triple antibiotic paste is quite effective against E. fecalis, compared to calcium hydroxide[18]. The minocycline present in Triple antibiotic paste is most effective component according to both MIC and agar diffusion test. So therefore it was a conscious decision to take by triple antibiotic paste in this study.

According to the study results A.indica showed the maximum antimicrobial activity followed by M.oleifera+A.indica and the M.oleifera had the least antimicrobial activity against E.faecalis and C.albicans.

\section{Conclusion:-}

In conclusion, according to this study, Azadirachta indica and Moringa oleifera demonstrated an antibacterial effect against Enterococcus Faecalis. Therefore, they could be considered as an alternative antimicrobial agent to use in root canal therapy. However, further studies are required to clarify the optimal concentration, cell toxicity and physical stability before its clinical application. 


\section{References:-}

1. Madhavan S,Muralidharan .comparing the antibacterial efficacy of intracanal medicaments in combination with clove oil against enterococcus faecalis. Asian J Pharm Clin Res,2015; 8(5): 136-138

2. Patel V, Santerre JP, Friedman S. Suppression of bacterial adherence by experimental root canal sealers. J Endod 2000;26(1):20-4

3. Mohanty S, Ramesh S, Muralidharan NP. Antimicrobial efficacy of apple cider vinegar against Enterococcus faecalis and Candida albicans: An in vitro study. J Adv Pharm Edu Res 2017;7(2):137-141

4. Bohora A, Hegde V , Kokate S .Comparison of the antibacterial efficiency of neem leaf extract and $2 \%$ sodium hypochlorite against E. faecalis, C. albicans and mixed culture - An in vitro study.Endodontology

5. Joshua D,Maki J,Babcall J.Invitro comparison effects of various endodontic medicaments on Enterococcus faecalis,J Endod 2007;33(5):567-569

6. Siqueira JF Jr,Lopes HP.Mechanisms of antimicrobial activity of calcium hydroxide:A critical review.Int Endod J 1999:32(5):361-9

7. Sundqvist G, Figdor D, Persson S, Sjögren U. Microbiologic analysis of teeth with failed endodontic treatment and the outcome of conservative re-treatment.Oral Surg Oral Med Oral Pathol Oral Radiol Endod. 1998 Jan;85(1):86-93.

8. Ashraf H, Samiee M, Eslami G, Ghodse Hosseini MR. Presence of Candida Albicans in Root Canal System of Teeth Requiring Endodontic Retreatment with and without Periapical Lesions. Iran Endod J. 2007;2(1):2428.

9. Mistry KS, Sanghvi Z, Parmar G, Shah S. The antimicrobial activity of Azadirachta indica, Mimusops elengi, Tinospora cardifolia, Ocimum sanctum and $2 \%$ chlorhexidine gluconate on common endodontic pathogens: An in vitro study.Eur J Dent. 2014 Apr;8(2):172-7

10. Charles H, Stuart, Scott A Schwartz, Thomas B, Cristopher B. Enterococcus Faecalis: Its Role In Root Canal Treatment Failure And Current Concepts In Retreatment J Endod 2006;32(2): 93-98.

11. Sedgley C, Buck G, Applebe O. Prevalence Of Enterococcus Faecalis At Multiple Oral Sites In Endodontic Patients Using Culture And PCR. J Endod 2006; 32(2): 104-09.

12. Siqueira, J. F., \& Sen, B. H. Fungi in endodontic infections. Oral Surgery, Oral Medicine, Oral Pathology, Oral Radiology, and Endodontology, 2004 May;97(5): 632-641.

13. Challa, Krishna. Antimicrobial activity of Azadirachta Indica (neem) leaf, bark and seed extracts. international journal of research and phytochemistry \& pharmacology.2013. 3. 1-4.

14. AnwarF, Latif S, Ashraf M,Gilani HA, Moringa oleifera: a food plant with multiple medicinal uses.January2007;21(1):17-25

15. Subapriya R. and Nagini S. Medicinal properties of neem leaves: a review. Curr Med Chem Anticancer Agents 2005; 5:149-6.

16. Lakshmi T., Krishnan V., Rajendram R., Madhusudhanan N. Azadirachta indica: a herbal panacea in dentistryan update. Pharmacognosy Reviews. 2015;9(17):41-44

17. Arévalo-Híjar L, Aguilar-Luis MÁ, Caballero-García S, Gonzáles-Soto N, Del Valle-Mendoza J. Antibacterial and Cytotoxic Effects of Moringa oleifera(Moringa) and Azadirachta indica (Neem) Methanolic Extracts against Strains of Enterococcus faecalis. Int J Dent. 2018;2018:1071676.

18. Adl A, Shojaee NS, Motamedifar M. A Comparison between the Antimicrobial Effects of Triple Antibiotic Paste and Calcium Hydroxide Against Entrococcus Faecalis. Iran Endod J. 2012;7(3):149-155. 